\title{
Rhabdias kongmongthaensis sp. n. (Nematoda: Rhabdiasidae) from Polypedates leucomystax (Amphibia: Anura: Rhacophoridae) in Thailand
}

\author{
Yuriy Kuzmin ${ }^{1}$, Vasyl V. Tkach ${ }^{2}$ and Jefferson A. Vaughan ${ }^{2}$ \\ ${ }^{1}$ Department of Parasitology, Institute of Zoology, 15 Bogdan Khmelnytsky Street, Kyiv, 01601, Ukraine; \\ ${ }^{2}$ Department of Biology, University of North Dakota, 1 Campus Drive and Cornell Street, Grand Forks, ND 58202, USA
}

Key words: Nematoda, Rhabdiasidae, Rhabdias kongmongthaensis, tree frogs, Rhacophoridae, Polypedates leucomystax, Thailand

\begin{abstract}
Rhabdias kongmongthaensis sp. $\mathrm{n}$. is described based on specimens found in the lungs of the tree frog Polypedates leucomystax (Gravenhorst) (Amphibia: Rhacophoridae) from Kanchanaburi Province, western Thailand. The new species is similar to two North-American species, Rhabdias ranae and $R$. americanus, by presence of two lateral pseudolabia, each with two inner submedian protuberances. R. kongmongthaensis differs from both species by relative length and shape of the tail, and by its distribution and host specificity. Presence of lateral pseudolabia distinguishes the new species from the geographically closest Rhabdias species as well as from those parasitizing other rhacophorid frogs.
\end{abstract}

Of about 40 species of the genus Rhabdias Stiles et Hassall, 1905, nine were described from anuran amphibians in Southeast Asia. Three of them, R. bicornis Lu, 1934, R. brachylaimus (Linstow, 1903) and R. incerta Wilkie, 1930, are specific parasites of toads $(\mathrm{Bu}-$ fonidae). Three other species, namely $R$. montana Yamaguti, 1954, R. multiproles Yuen, 1965 and $R$. nipponica Yamaguti, 1935, were found in frogs belonging to the family Ranidae. Rhabdias globocephala Kung et $\mathrm{Wu}, 1945$ was originally described from a microhylid tree frog, Microhyla ornata, and later found in a rhacophorid species, Buergeria pollicaris, collected in China (Kuzmin 2005). Rhabdias polypedatis Yamaguti, 1941 and $R$. rhacophori Yamaguti, 1941 were described from rhacophorid frogs in Japan (Yamaguti 1941).

Polypedates leucomystax (Gravenhorst) is a rather common rhacophorid tree frog widely distributed in South East Asia from eastern India to Sumatra, Philippines and Ryukyus archipelago; it is regarded that the populations in the latter two regions are introduced. In April 2004 we collected Rhabdias from lungs of several specimens of Polypedates leucomystax in western Thailand. They appeared to be different from all known species of the genus and are described herein as belonging to a new species, Rhabdias kongmongthaensis sp. $\mathrm{n}$.

\section{MATERIALS AND METHODS}

Thirteen specimens of Polypedates leucomystax were collected in the Kong Mong Tha village, Kanchanaburi Province, Thailand and examined for presence of helminths. Four frogs harboured lung nematodes of the genus Rhabdias. After recovery from the host lungs, the nematodes were rinsed in saline, heat-killed in saline and stored in $70 \%$ ethanol. For morphological examination, nematodes were cleared in glycerin- phenol mixture. Holotype and paratypes are deposited in the United States National Parasite Collection (USNPC), Beltsville, Maryland. All measurements are in micrometres unless otherwise stated.

\section{RESULTS}

Rhabdias kongmongthaensis sp. $\mathrm{n}$.

Fig. 1

Description. Measurements are given for holotype followed by mean values and limits for 9 paratypes. Relatively large Rhabdias species. Body 10.975 (9.708; 6.475-12.275) mm long and 320 (251; 200-310) wide at level of vulva. Body cuticle inflated. Oral opening narrow, oval, two lateral pseudolabia and four submedian lips present; each lip bearing small papilla on top. Lateral papillae situated on inner surface of pseudolabia. Buccal capsule infundibuliform in lateral view, circular in apical view, $15(14 ; 12-15)$ wide and 12 (12; 10-15) deep; walls of buccal capsule completely surrounded with oesophagus anterior end. Oesophagus club-shaped, comparatively narrow, with mostly muscular anterior part and glandular posterior part. Muscular part slightly dilated at its mid-length. Posterior oesophageal bulb elongate, egg-shaped. Oesophagus length $610(589 ; 530-630)$, or $5.6(6.3 ; 5.1-8.8) \%$ of body length. Width of oesophagus anterior end $32(34 ; 32-$ $35)$, width of muscular dilation $45(44 ; 40-50)$, minimum width of glandular part $37(38 ; 32-42)$, width of posterior bulb 67 (66;57-77). Nerve ring encircling oesophagus posterior to its muscular dilation, at 210 (229; 200-250) from oesophagus anterior end. This distance constitutes $34.4(39 ; 34.5-42.1) \%$ of oesophagus length. Intestine wide, thick-walled, its anterior end

Address for correspondence: V. Tkach, Department of Biology, University of North Dakota, 1 Campus Drive and Cornell Street, 101 Starcher Hall, Grand Forks, ND 58202-9019, USA. Phone: ++1 701777 4675; Fax: ++1 701777 2623; E-mail: vasyl.tkach@und.nodak.edu 


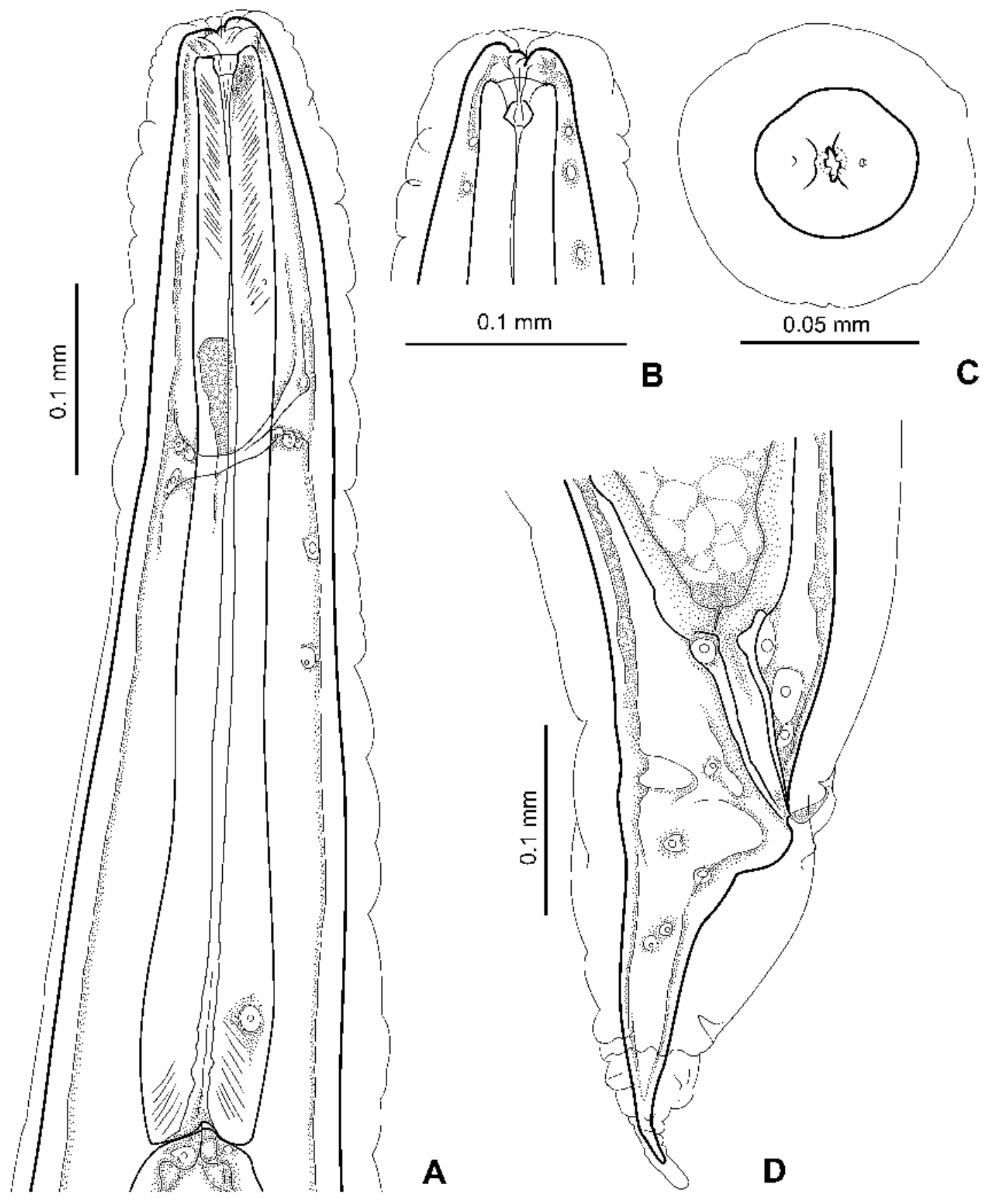

Fig. 1. Rhabdias kongmongthaensis sp. n. A - anterior end, lateral view; $\mathbf{B}$ - head end, dorsal view; $\mathbf{C}$ - head end, apical view; D - tail, lateral view.

narrower than posterior bulb of oesophagus. Posterior part of intestine comparatively thin-walled, with wide lumen filled with black contents. Rectum short, narrow, with sclerotized walls.

Hermaphrodites. Genital system amphidelphic, typical of Rhabdias. Vulva post-equatorial. Distance from anterior end to vulva $5.700(5.187 ; 3.675-6.375) \mathrm{mm}$, or $51.9(54.4 ; 51.6-57.0) \%$ of body length. Uteri filled with numerous eggs, most eggs containing larvae.
Tail comparatively short, conical, tail tip covered with cuticular swelling. Tail length $200(217 ; 180-250)$ or $1.8(2.3 ; 1.9-3.1) \%$ of body length.

$\mathrm{T}$ y $\mathrm{p}$ e $\mathrm{h}$ o s t: Stripe (house, jar) tree frog, Polypedates leucomystax (Gravenhorst, 1829).

T y p e 1 o c a 1 i t y : Kong Mong Tha, Kanchanaburi Province, Thailand $\left(15^{\circ} 10^{\prime} \mathrm{N}, 98^{\circ} 32^{\prime} \mathrm{E}\right)$.

Site of infection: Lungs. 
Prevalence and intensity: 4 out of $13(30.8 \%)$ tree frogs were infected with 1-4 (mean 2.7) nematodes.

T y p e s e r i e s : Holotype, USNPC 96376; 9 paratypes, USNPC 96377.

E t y m o lo g y : Species name is given after the Kong Mong Tha village in Thailand, the type locality of the species.

Remarks. Rhabdias kongmongthaensis is morphologically most similar to Rhabdias ranae Walton, 1929, a parasite of North American frogs, and $R$. americanus Baker, 1978, a parasite of North American toads. The three species share common features of the head end morphology, namely the presence of two lateral pseudolabia and four submedian lips or "protuberances" (terminology of Baker 1978) surrounding the oval oral aperture. Rhabdias kongmongthaensis differs from $R$. ranae in a more elongate body and a relatively shorter tail; the tail comprises $3.7-5.4 \%$ of body length in the latter species (Kuzmin et al. 2003). Rhabdias kongmongthaensis has a cuticular swelling that reaches the tip of tail. This swelling is absent in $R$. ranae. In $R$. americanus, the nerve ring is situated closer to the anterior end of oesophagus than in R. kongmongthaensis. The two species also differ in shape of the tail, which is narrower and more elongate in $R$. americanus (Kuzmin et al. 2003). We also consider important the substantial geographical isolation and different host groups of $R$. kongmongthaensis versus $R$. americanus and $R$. ranae.

Rhabdias kongmongthaensis is geographically close to $R$. brachylaimus (Linstow, 1903), R. globocephala Kung et Wu, 1945, $R$. nipponica Yamaguti, 1935 and $R$. multiproles Yuen, 1965, all found in mainland South East Asia. However, lateral pseudolabia or similar structures on the head end have not been described for any of these species. In $R$. brachylaimus, the oral opening is surrounded by "three lips which protrude abruptly at the head end" (Yuen 1965, p. 276); in R. multiproles, six poorly developed lips are present (Yuen 1965); no lips were reported in $R$. nipponica (Yamaguti 1935). In $R$. globocephala, the round oral opening is surrounded by six small lips (Kung and Wu 1945, Kuzmin 2005). Additionally, $R$. kongmongthaensis differs from $R$. globocephala by less pronounced swelling of the muscular oesophagus (Kuzmin 2005).

Two species of the genus Rhabdias have been described from the rhacophorid frogs from Japan, namely $R$. polypedatis Yamaguti, 1941 and $R$. rhacophori Yamaguti, 1941. It was stated in the first descriptions that lips or pseudolabia were lacking in both of them (Yamaguti 1941). Both $R$. polypedatis and $R$. rhacophori were recently synonymised with $R$. nipponica Yamaguti, 1935 by Goldberg and Bursey (2002). We do not comment on the synonymisation here, however, it is obvious that $R$. kongmongthaensis clearly differs from $R$. polypedatis, $R$. rhacophori and $R$. nipponica in the structure of the head end.

\section{DISCUSSION}

Differentiation among species belonging to the genus Rhabdias Stiles et Hassall, 1905 is often complicated due to their high morphological uniformity (Chu 1936, Baker 1978). A few species may be easily distinguished from others by the presence of unique and distinct morphological characters, such as the shape of the cuticular swelling on the anterior end, presence of two pseudolabia at the anterior end or reduction of the rectum (Goodey 1924, Lu 1934, Kung and Wu 1945, Baker 1978, Kuzmin 2000, 2003). Morphology of the anterior end of Rhabdias species, in some instances, yields some characters appropriate for the species diagnostics. Baker (1978) was the first to propose division of Rhabdias species into three groups based on the morphology of their head end: species without lips, species with six lips and species with two lateral pseudolabia. Rhabdias kongmongthaensis belongs to the third group, since lateral inflations of the body wall on its head end are very similar to the lateral pseudolabia described by Baker (1978) in R. americanus and $R$. ranae.

Although we examined for helminths only four amphibian species (Polypedates leucomystax plus one species of ranid frogs and two toad species) from the type locality of $R$. kongmongthaensis, we suggest that the new species is a specific parasite of tree frogs. More and more data, including those obtained using DNA sequences (our unpublished data), provide evidence that the host specificity of most Rhabdias is narrower than traditionally suggested. For instance, $R$. ranae, previously thought to have a wide host range and distributed almost all over North America, has been recently demonstrated to represent at least four different species $(R$. ranae, $R$. ambystomae, $R$. joaquinensis and $R$. bakeri) that are either specific to different host groups (salaman-ders, wood frogs, leopard frogs) or differ in their geographic distribution (Kuzmin et al. 2001, 2003, Tkach et al., in press). We anticipate that the rich amphibian fauna of Thailand and other regions in South East Asia harbours numerous species of Rhabdiasidae that still await their discovery.

Acknowledgements. We are grateful Dr. Greg Schneider (Museum of Zoology, University of Michigan at Ann Arbor) for the identification of the tree frog species. This study was supported by the National Science Foundation through North Dakota EPSCoR (grant no. 0132289) and the National Institutes of Health (R01AI48813 to JAV). 


\section{REFERENCES}

BAKER M.R. 1978: Morphology and taxonomy of Rhabdias spp. (Nematoda: Rhabdiasidae) from reptiles and amphibians of southern Ontario. Can. J. Zool. 56: 21272141.

CHU T. 1936: A review of the status of the reptilian nematodes of the genus Rhabdias with a description of Rhabdias fuscovenosa var. catanensis (Rizzo, 1902) new rank. J. Parasitol. 22: 130-139.

GOLDBERG S.R., BURSEY C.R. 2002: Helminths of 10 species of anurans from Honshu Island, Japan. Comp. Parasitol. 69: 162-176.

GOODEY T. 1924: Two new species of the nematode genus Rhabdias. J. Helminthol. 2: 203-208.

KUNG C.C., WU H.W. 1945: Parasitic nematodes of amphibians from Pehpei Szechwan, China. Sinensia 16: 73 83.

KUZMIN Yu.I. 2000: Morphology of parasitic and free-living adults of Rhabdias rubrovenosa (Nematoda: Rhabdiasidae). Vestn. Zool. 34 (1/2): 109-114.

KUZMIN Y. 2003: Rhabdias japalurae sp. nov. (Nematoda, Rhabdiasidae) from the japalures (Reptilia, Agamidae) and some notes on other Rhabdias spp. from lizards. Acta Parasitol. 48: 6-11.

KUZMIN Yu.I. 2005: The description of Rhabdias globocephala Kung et Wu, 1945 (Nematoda: Rhabdiasidae) from the new host Buergeria pollicaris (Werner, 1914) (Amphibia: Rhacophoridae). Vestn. Zool. 39 (4): 9-14.

KUZMIN Y., TKACH V.V., SNYDER S.D. 2001: Rhabdias ambystomae sp. n. (Nematoda: Rhabdiasidae) from the North American spotted salamander Ambystoma maculatum (Amphibia: Ambystomatidae). Comp. Parasitol. 68: 228-235.

KUZMIN Y., TKACH V.V., SNYDER S.D. 2003: The nematode genus Rhabdias (Nematoda: Rhabdiasidae) from amphibians and reptiles of the Nearctic. Comp. Parasitol. 70: 101-114.

LU S.C. 1934: On Rhabdias, a genus of parasitic nematoda of Nanking. Sinensia 5: 164-172.

TKACH V.V., KUZMIN Y., PULIS E.E.: A new species of Rhabdias from lungs of the wood frog, Rana sylvatica, in North America: the last sibling of Rhabdias ranae? J. Parasitol. (In press.)

YAMAGUTI S. 1935: Studies on the helminth fauna of Japan. Pt. 10. Amphibian nematodes. Jpn. J. Zool. 6: 393-402.

YAMAGUTI S. 1941: Studies on the helminth fauna of Japan. Pt. 34. Amphibian nematodes, II. Jpn. J. Zool. 9: 397-408.

YUEN P.H. 1965: Some studies on the taxonomy and development of some rhabdiasoid and cosmocercoid nematodes from Malayan amphibians. Zool. Anz. 174: 275-298. 